\title{
CHANGES IN GROWTH PARAMETERS, OIL YIELD, FATTY ACID COMPOSITION AND MINERAL CONTENT OF TWO SAFFLOWER (CARTHAMUS TINCTORIUS L.) GENOTYPES IN RESPONSE TO WATER STRESS
}

\author{
OZKAN, A. \\ Department of Gastronomy and Culinary Arts Faculty of Fine Arts, Gaziantep University, \\ 27000 Gaziantep, Turkey \\ (e-mail:aozkan27@gmail.com)
}

(Received $9^{\text {th }}$ Sep 2019; accepted $15^{\text {th }}$ Nov 2019)

\begin{abstract}
The present study was designed to investigate the effects of water stress on growth and development parameters, oil yield coupled with their fatty acid composition as well as mineral content of two safflower genotypes including Remzibey-05 and Gokturk. Accordingly, significant differences regarding plant length, branch number per plant, capsule number per plant, capsule seed number, 1000seed weight and seed yield per pot were assessed. However, first branch length did not exhibit significant differences between genotypes in response to the treatments. Furthermore, Oil yield was not significantly affected by severe water stress for Remzibey- 05 even a $1.60 \%$ increase was observed under severe water stress but the yield was significantly increased by $2.37 \%$ in Gokturk. In terms of oil composition unsaturation degree, UFA/SFA significantly increased with stress for both genotypes. Concerning mineral content; Remzibey - 05 genotype had the highest value of K and Na whereas Gokturk genotype had the highest values of $\mathrm{Mg}, \mathrm{Fe}, \mathrm{Cu}$ and $\mathrm{Zn}$. Finally, the experimental groups were discriminated and identified using PCA and heatmap visualization.
\end{abstract}

Keywords: fatty acid unsaturation degree, drought, Remzibey-05, Gokturk, water stress

\section{Introduction}

Water stress resistance of crops is one of the great challenges for the world's agricultural systems. Water stress-induced loss in crop yield probably exceeds losses caused by other severe environmental constraints. Thereby, numerous researches in plants responses to water scarcity has been important interest for scientists for many years in order to develop, improve or explore drought-tolerant plant species or cultivars, genotypes within the same species for a sustainable agricultural production (Hamrouni et al., 2001; Turk et al., 2004; Al-Barrak, 2006; Bettaieb et al., 2009; Ozkan and Kulak, 2013; Zandalinas et al., 2018; Fahad et al., 2017; Shi et al., 2017; Ahmed et al., 2016; Ozkan, 2018; Rubin et al., 2017; Vurukonda et al., 2016; Pouri et al., 2019; Cetinkaya et al., 2016).

Water stress alters the biochemical synthesis pathways and subsequently production of primary and secondary metabolites is influenced. It is worthy to remark that industrially, medicinally or economically important metabolites may be accumulated beyond the decline in the growth and productivity of crops (Ozkan and Kulak, 2013; Hamrouni et al., 2001; Laribi et al., 2009). Of those, the variations in lipid content and its composition have been reported under varying irrigation degrees (Laribi et al., 2009; Bettaieb et al., 2010; Laribi et al., 2011; Ozkan and Kulak, 2013).

Safflower (Carthamus tinctorius) belonging to Asteraceae family is of the oldest cultivated oilseed crop but not common and not very popular when compared to other oil crops such as soybean, sunflower and peanut (Canavar et al., 2014; Bortolheiro and Silva, 2017). Of the oilseed crops, safflower has been well-documented to possess 
ability in moderate tolerance of environmental constraints but changes in oil yield and subsequently fatty acid composition have been reported, indicating that water constraints water deficient condition might cause increase protein and decrease oil contents of safflower (Nabipour et al., 2007; Amini et al., 2014; El Sabagh et al., 2019). Seed oil of safflower is well characterized with a large amount of saturated (palmitic and stearic) and unsaturated (oleic, linoleic and linolenic) fatty acids and composition. However, the percentage and content of the compounds and oil yield are particularly affected by water stress (Bortolheiro and Silva, 2017; Nabipour et al., 2007; Ashrafi and Razmjoo, 2010; Eslam, 2011; Amini et al., 2014; Ozkan and Kulak, 2013; Nazari et al., 2017). Since each species of the plants have been comprised of genotypes, cultivars, varieties, populations and chemotypes, many studies can be performed on the different genotypes of the same species. As well-known and documented that, plants have been adapted to environmental conditions through not only based their genetic inheritance and but also the primary and secondary metabolites inside. Through profiling the metabolite content, plants have been sorted as tolerant or sensitive. Along with the present study, two different safflower genotypes were used in order to determine their oil yield combined with fatty acid compositional profiling in response to water stress conditions. In addition to the oil and its composition, mineral content or accumulation of seed samples belonging to both genotypes were determined. Furthermore, growth and developmental parameters of genotypes were compared after subjection water stress and normal life span under irrigated conditions (control).

\section{Materials and methods}

\section{Plant material and water deficit treatment}

Experiments were performed under greenhouse conditions with pots including $2 \mathrm{~kg}$ soil mixture of 3:1:1 (soil-peat-perlite) at Gaziantep, Turkey. The experiments were carried out with three replicates corresponding 10 plants for each replicate. Each pot included one plant seedling. The effects of severe water stress (SWD) on safflower genotypes (Remzibey-05 and Gokturk) were investigated. The safflower genotypes are of the significant oil crops. The materials used herein are of the developed in Turkey. Herewith, the studies regarding adaptation of the genotypes in arid and semiarid regions corresponding to the limited water sources are required. In this context, the genotypes were screened for their low water content tolerance corresponding to the oil yield coupled with their fatty acid composition in addition to basic agricultural parameters.

For the experimental processes, similar methods with Bettaieb et al. (2009) were followed. In brief, during the first 35 days of the study, plants were irrigated with tap water, and subsequently exposed to different water regimes: 100\% (control group: C; $600 \mathrm{ml}$ ) 25\% (severe water deficit group: SWD; $150 \mathrm{ml}$ ) of field capacity (FC). The properties of experimental soils were as follows: Potassium $(297.75 \mathrm{ppm})$, organic matter (1.16\%), salt (0.059) at a set $\mathrm{pH}(8.0)$. Experiments were conducted in a greenhouse with a 14-h photoperiod and performed between October 13, 2018 and July 26, 2019. Mean temperature was kept at $25 \pm 2{ }^{\circ} \mathrm{C}$ during daytime and $14 \pm 2{ }^{\circ} \mathrm{C}$ at nighttime, respectively, with a relative humidity of $70 \%$. After harvest, seeds were airdried and stored at $4{ }^{\circ} \mathrm{C}$ until use for further analysis. 


\section{Growth and yield parameter measurements}

For each treatment, measurement of plant length, seed number per capsule, capsule number, 1000-seed weight, total weight per pot, and single plant yield were evaluated by harvest of six randomly selected plants from each experimental replicate (Ozkan and Kulak, 2013; Ozkan, 2018).

\section{Oil extraction and fatty acid composition analysis}

Oil extraction and then fatty acids of oil were determined according to our previous methods applied (Ozkan and Kulak, 2013; Ozkan, 2018). Briefly, oils were extracted from safflower seeds (each $2 \mathrm{~g}$ sample) with $\mathrm{n}$-hexane for $4 \mathrm{~h}$ using a Soxhlet extraction apparatus. Subsequently, the solvent was evaporated under reduced pressure and temperature using a Rotary evaporator (Heidolph). $0.1 \mathrm{~g}$ of safflower oil was added to $2 \mathrm{ml} \mathrm{n}$-heptanes into a screw-capped tube for esterification. The fatty acid analyses were conducted according to the official method COI/T.20/Doc.no.24 2001. $0.1 \mathrm{~g}$ of safflower oil was taken into screw-capped tube. $2 \mathrm{ml}$-heptane was added and shaken. After $0.2 \mathrm{ml}$ methanolic potassium hydroxide was added for esterification, tubes were vigorously shaken for $30 \mathrm{~s}$ after the vials were closed. The supernatant of the solution was taken followed after $1 \mathrm{~h}$ of incubation at room temperature. Then, the supernatant was put in $2 \mathrm{ml}$ vials for injection.

\section{Fatty acid composition profile determination}

GC-FID analyses of fatty acids methyl esters were carried out on a Shimadzu gas chromatography (GC2010 series) equipped with a Supelco SP 2380 fused silica capillary column $(100 \mathrm{~m}, 0.25 \mathrm{~mm}$ i.d., $0.2 \mu \mathrm{m}$ film thickness). Helium was used as carrier gas, at a flow rate of $3 \mathrm{~mL} / \mathrm{min}$. The injection and detector temperature were $140{ }^{\circ} \mathrm{C}$ and $240{ }^{\circ} \mathrm{C}$, respectively. The oven temperature was held isothermal at $140{ }^{\circ} \mathrm{C}$ for $5 \mathrm{~min}$, then raised to $240{ }^{\circ} \mathrm{C}$ at $4{ }^{\circ} \mathrm{C} / \mathrm{min}$ and held isothermal at $240{ }^{\circ} \mathrm{C}$ for $15 \mathrm{~min}$. Injection volume of Diluted samples $[1 / 100(\mathrm{v} / \mathrm{v})$ in $\mathrm{n}$-heptanes] of $1.0 \mu \mathrm{L}$ were injected automatically in the split mode (1/100). The identification of the constituents was based on comparison of the GC-retention times with those of available analytical standards (Larodan Fine chemicals, mixture of 37 components of fatty acids methyl esters). Peak area was used to obtain the percentage of individual fatty acid.

\section{Sample preparation and measurement for mineral content}

The harvested seed samples were cleaned, washed by de-ionized water, and dried. Pre-dried samples were de-moisturized at $70^{\circ} \mathrm{C}$ for $48 \mathrm{~h}$ in an oven and ground for chemical analysis. $0.2 \mathrm{~g}$ of ground powdered seed samples were immediately placed into burning cup with $5 \mathrm{ml} \mathrm{HNO}_{3} 65 \%$ and $2 \mathrm{ml} \mathrm{H}_{2} \mathrm{O}_{2} 30 \%$. After the incineration process, the solution was cooled at room temperature for $45 \mathrm{~min}$. The extracts were passed through a Whatman 42 filter paper. These filtrates were collected by de-ionized water in a $20 \mathrm{ml}$-polyethylene bottles and kept at $4{ }^{\circ} \mathrm{C}$ in laboratory for ICP-OES analysis. Each sample was analyzed in triplicate.

\section{Statistical analysis}

SPSS statistical program was used to determine statistical significance levels by employing the independent one-way ANOVA followed by Duncan multiple range test 
and the differences between individual means were considered to be statistically important at $\mathrm{p}<0.05$. Moreover, specifically for each genotype, control and stress group of plants were compared using independent t-test in order to determine to clarify their behaviour against stress. Also, the discrimination for experimental groups was done with the principal component analysis using SPSS software. Finally, heatmap was 209 constructed using ClustVis (https://biit.cs.ut.ee/clustvis/).

\section{Results and discussion}

\section{Effect of water stress on plant growth and development parameters}

Based on independent $t$-test, there were significant differences between plant length $(t=2.274 ; p<0.05)$, capsule seed number $(t=3.688 ; p<0.01), 1000$-seed weight $(t=2.333 ; p<0.05)$, seed yield per pot $(t=5.231 ; p<0.01)$ for Remzibey-05 genotype in response to water stress. However, first branch length, branch number per plant and capsule number per plant did not exhibit significant differences between treatments $(p>0.05)($ Table 1$)$.

Table 1. $t$-test analysis of growth and yield parameters of Remzibey-05 genotype exposed to water stress

\begin{tabular}{c|c|c|c|c}
\hline Growth and yield parameters & Control & SWD & t-statistic & p value \\
\hline Plant length $(\mathrm{cm})$ & $37.50 \pm 6.02$ & $29.33 \pm 6.41$ & 2.274 & $0.046^{*}$ \\
First branch length $(\mathrm{cm})$ & $18.50 \pm 6.29$ & $17.33 \pm 5.57$ & 0.340 & 0.741 \\
Branch number per plant & $4.83 \pm 1.33$ & $3.83 \pm 1.17$ & 1.384 & 0.197 \\
Capsule number per plant & $5.83 \pm 2.23$ & $3.83 \pm 1.17$ & 1.947 & $0.080^{\sim}$ \\
Capsule seed number & $30.17 \pm 9.70$ & $15.34 \pm 1.70$ & 3.688 & $0.004^{* *}$ \\
1000-seed weight $(\mathrm{g})$ & $51.66 \pm 14.09$ & $35.20 \pm 10.01$ & 2.333 & $0.042^{*}$ \\
Seed yield per pot $(\mathrm{g})$ & $5.99 \pm 1.44$ & $2.40 \pm 0.87$ & 5.231 & $0.000^{* *}$ \\
\hline
\end{tabular}

$* * \mathrm{p}<0.01 ; * \mathrm{p}<0.05 ; \sim \mathrm{p}<0.10$; SWD: severe water deficit

Severe water stress significantly affected plant length $(t=3.353 ; p<0.01)$, branch number per plant $(\mathrm{t}=3.835 ; \mathrm{p}<0.01)$, capsule number per plant $(t=4.715 ; p<0.01)$, capsule seed number $(3.664 ; \mathrm{p}<0.01)$, seed yield per plant $(t=8.871 ; p<0.01)$ in Gokturk genotype. However, first branch length $(t=0.902 ; p>0.05)$ and 1000-seed weight $(\underline{t}=1.987 ; p>0.05)$ did not differ in Gokturk genotype in response to severe water stress (Table 2).

Table 2. t-test analysis of growth and yield parameters of Gokturk genotype exposed to water stress

\begin{tabular}{c|c|c|c|c}
\hline Growth and yield parameters & Control & SWD & t-statistic & p value \\
\hline Plant length $(\mathrm{cm})$ & $34.00 \pm 5.514$ & $22.83 \pm 6.014$ & 3.353 & $0.007^{* *}$ \\
First branch length $(\mathrm{cm})$ & $18.17 \pm 6.113$ & $14.83 \pm 6.68$ & 0.902 & 0.388 \\
Branch number per plant & $4.83 \pm .41$ & $3.17 \pm .98$ & 3.835 & $0.003^{* *}$ \\
Capsule number per plant & $6.00 \pm 1.10$ & $3.17 \pm .98$ & 4.715 & $0.001^{* *}$ \\
Capsule seed number & $23.67 \pm 7.71$ & $11.74 \pm 2.03$ & 3.664 & $0.004^{* *}$ \\
1000-seed weight (g) & $49.85 \pm 7.21$ & $40.91 \pm 8.34$ & 1.987 & $0.075 \sim$ \\
Seed yield per pot (g) & $5.29 \pm .82$ & $1.54 \pm .64$ & 8.871 & $0.000^{* *}$ \\
\hline
\end{tabular}

$* * \mathrm{p}<0.01 ; \sim \mathrm{p}<0.10$; SWD: severe water deficit 
Furthermore, independent t-test was performed in order to determine the differences between control and stress groups of genotypes. No differences were observed for the parameters of both genotypes in control groups (Table 3). Also, there were no significant differences-except capsule seed number between genotypes under severe stress conditions (Table 4).

Table 3. $t$-test analysis of growth and yield parameters of both genotypes under irrigated conditions (control)

\begin{tabular}{c|c|c|c|c}
\hline Growth and yield parameters & $\begin{array}{c}\text { Remzibey-05 } \\
\text { control }\end{array}$ & $\begin{array}{c}\text { Gokturk } \\
\text { control }\end{array}$ & t-statistic & p value \\
\hline Plant length $(\mathrm{cm})$ & $37.50 \pm 6.03$ & $34.00 \pm 5.52$ & 1.050 & 0.319 \\
First branch length $(\mathrm{cm})$ & $18.50 \pm 6.29$ & $18.17 \pm 6.11$ & 0.093 & 0.928 \\
Branch number per plant & $4.83 \pm 1.33$ & $4.83 \pm 0.41$ & 0.000 & 1.000 \\
Capsule number per plant & $5.83 \pm 2.23$ & $6.00 \pm 1.10$ & -0.164 & 0.873 \\
Capsule seed number & $30.17 \pm 9.71$ & $23.67 \pm 7.71$ & 1.285 & 0.228 \\
1000-seed weight $(\mathrm{g})$ & $51.66 \pm 14.1$ & $49.85 \pm 7.21$ & 0.281 & 0.785 \\
Seed yield per pot $(\mathrm{g})$ & $5.99 \pm 1.44$ & $5.3 \pm .82$ & 1.045 & 0.320 \\
\hline
\end{tabular}

Table 4. $t$-test analysis of growth and yield parameters of both genotypes under severe water stress

\begin{tabular}{c|c|c|c|c}
\hline Growth and yield parameters & $\begin{array}{c}\text { Remzibey-05 } \\
\text { SWD }\end{array}$ & $\begin{array}{c}\text { Gokturk } \\
\text { SWD }\end{array}$ & t-statistic & p value \\
\hline Plant length $(\mathrm{cm})$ & $29.33 \pm 6.41$ & $22.83 \pm 6.02$ & 1.812 & 0.100 \\
First branch length $(\mathrm{cm})$ & $17.33 \pm 5.57$ & $14.83 \pm 6.68$ & .704 & 0.497 \\
Branch number per plant & $3.83 \pm 1.17$ & $3.17 \pm 0.98$ & 1.069 & 0.310 \\
Capsule number per plant & $3.83 \pm 1.17$ & $3.17 \pm 0.98$ & 1.069 & 0.310 \\
Capsule seed number & $15.34 \pm 1.70$ & $11.75 \pm 2.03$ & 3.327 & $0.008^{* *}$ \\
1000-seed weight $(\mathrm{g})$ & $35.20 \pm 10.00$ & $40.90 \pm 8.34$ & -1.073 & 0.308 \\
Seed yield per pot $(\mathrm{g})$ & $2.40 \pm 0.875$ & $1.54 \pm 0.64$ & 1.959 & $0.079 \sim$ \\
\hline
\end{tabular}

$* * \mathrm{p}<0.01 \sim \mathrm{p}<0.10$; SWD: severe water deficit

One-way variance analysis reveals significant differences in terms of plant length $(F=6.708 ; p<0.01)$, branch number per plant $(F=3.750 ; p<0.05)$, capsule number per plant $(F=5.719 ; p<0.01)$, capsule seed number $(F=10.289 ; p<0.01), 1000$-seed weight $(F=3.413 ; p<0.05)$ and seed yield per pot $(F=28.921 ; p<0.01)$. However, first branch length did not exhibit significant differences between genotypes in response to the treatments (Table 5).

In many and various studies regarding water stress and agronomical yield attributes interaction, stress conditions have been reported to exhibit inhibitory impacts on stem growth and plant height due to shrinkage in output changes in cellular water status of the plant. The effects of the water stress on the plant parts are variable for the examined parameters. The effects can be observed at certain developmental stages of the plant, a trait of the plant or genotypes of the same plant species (Prasad and Staggenborg, 2008). 
Table 5. One-way variance analysis of growth and yield parameters of genotypes in response to treatments

\begin{tabular}{c|c|c|c|c|c}
\hline $\begin{array}{c}\text { Growth and yield } \\
\text { parameters }\end{array}$ & $\begin{array}{c}\text { Remzibey-05 } \\
\text { control }\end{array}$ & $\begin{array}{c}\text { Remzibey-05 } \\
\text { SWD }\end{array}$ & $\begin{array}{c}\text { Gokturk } \\
\text { control }\end{array}$ & $\begin{array}{c}\text { Gokturk } \\
\text { SWD }\end{array}$ & $\begin{array}{c}\text { ANOVA } \\
\text { F-statistic }\end{array}$ \\
\hline Plant length $(\mathrm{cm})$ & $37.50 \pm 6.02 \mathrm{a}$ & $29.33 \pm 6.40 \mathrm{bc}$ & $34.00 \pm 5.51 \mathrm{ab}$ & $22.83 \pm 6.01 \mathrm{c}$ & $6.708^{* *}$ \\
First branch length $(\mathrm{cm})$ & $18.50 \pm 6.29$ & $17.33 \pm 5.57$ & $18.17 \pm 6.11$ & $14.83 \pm 6.68$ & .432 \\
Branch number per plant & $4.83 \pm 1.33 \mathrm{a}$ & $3.83 \pm 1.17 \mathrm{ab}$ & $4.83 \pm .401 \mathrm{a}$ & $3.17 \pm .98 \mathrm{~b}$ & $3.750^{*}$ \\
Capsule number per plant & $5.83 \pm 2.229 \mathrm{a}$ & $3.83 \pm 1.169 \mathrm{~b}$ & $6.00 \pm 1.095 \mathrm{a}$ & $3.17 \pm .983 \mathrm{~b}$ & $5.719^{* *}$ \\
Capsule seed number & $30.17 \pm 9.70 \mathrm{a}$ & $15.34 \pm 1.70 \mathrm{~b}$ & $23.67 \pm 7.71 \mathrm{a}$ & $11.74 \pm 2.03 \mathrm{~b}$ & $10.289^{* *}$ \\
1000-seed weight $(\mathrm{g})$ & $51.66 \pm 14.09 \mathrm{a}$ & $35.20 \pm 10.01 \mathrm{~b}$ & $49.85 \pm 7.21 \mathrm{a}$ & $40.90 \pm 8.34 \mathrm{ab}$ & $3.413^{*}$ \\
Seed yield per pot $(\mathrm{g})$ & $5.99 \pm 1.44 \mathrm{a}$ & $2.40 \pm 0.88 \mathrm{~b}$ & $5.30 \pm 0.82 \mathrm{a}$ & $1.54 \pm 0.64 \mathrm{~b}$ & $28.921^{* *}$ \\
\hline
\end{tabular}

Means \pm SD in the same row by the same letter are not significantly different to the test of Duncan $(\alpha=0.05) . * * p<0.01 * p<0.05$; SWD: severe water deficit

\section{Correlation analysis of growth and yield parameters of safflower}

Table 6 presents the correlation analysis of plant length, first branch length, number of branches, capsule number, seed number, 1000-seed weight and seed yield in Carthamus tinctorius genotypes. Significant and positive relation was observed by $64.2 \%$ between plant height and first branch length $(r=0.642 ; p<0.01)$. Also, 69.9\% ratio between plant length and branch number was found to be significant with positive correlation $(r=0.699 ; p<0.01)$. Plant length was also positively correlated with capsule number per plant by $80.4 \%(r=0.804 ; p<0.01)$. Plant length was furthermore positively correlated with seed yield per pot $(r=0.782 ; p<0.01)$. moreover, significant and positive correlation coefficients between first branch length and capsule number per plant $(r=0.417 ; p<0.05)$, first branch length and seed yield per pot $(r=0.465$; $p<0.05)$, branch number per plant and capsule number per plant $(r=0.900 ; p<0.01)$, branch number per plant and seed yield per pot $(r=0.742 ; p<0.01)$, capsule seed number and seed yield per pot $(r=0.790 ; p<0.01)$, capsule seed number and seed yield per pot $(r=0.727 ; p<0.01)$ as well as 1000 -seed weight and seed yield per pot $(r=0.508 ; p<0.05)$ were observed. The remained coefficients were all positive but not significant. No negative correlations were found between investigated parameters (Table 6).

Table 6. Correlation analysis of growth and yield parameters of safflower

\begin{tabular}{c|c|c|c|c|c|c|c}
\hline & $\begin{array}{c}\text { Plant } \\
\text { length }\end{array}$ & $\begin{array}{c}\text { First branch } \\
\text { length }\end{array}$ & $\begin{array}{c}\text { Branch number } \\
\text { per plant }\end{array}$ & $\begin{array}{c}\text { Capsule number } \\
\text { per plant }\end{array}$ & $\begin{array}{c}\text { Capsule seed } \\
\text { number }\end{array}$ & $\begin{array}{c}\text { 1000-seed } \\
\text { weight }\end{array}$ & $\begin{array}{c}\text { Seed yield } \\
\text { per pot }\end{array}$ \\
\hline Plant length & 1 & & & & & & \\
First branch length & $.642^{* *}$ & 1 & & & & & \\
Branch number per plant & $.699^{* *}$ & 0.39 & 1 & & & \\
Capsule number per plant & $.804^{* *}$ & $.417^{*}$ & $.900^{* *}$ & 1 & & \\
Capsule seed number & 0.395 & 0.228 & 0.322 & 0.294 & 1 & & \\
1000-seed weight & 0.336 & 0.219 & 0.288 & 0.279 & 0.26 & 1 & $.7267^{* *}$ \\
Seed yield per pot & $.782^{* *}$ & $.465^{*}$ & $.742^{* *}$ & $.790^{* *}$ & $.727^{* *}$ & $.508^{*}$ \\
\hline
\end{tabular}

$* * \mathrm{p}<0.01, * \mathrm{p}<0.05$ 


\section{Effects of water stress on oil yield and fatty acid composition}

Oil yield was not significantly affected with severe water stress in Remzibey-05 even a $1.60 \%$ increase was observed under severe water stress but the yield was significantly augmented by $2.37 \%$ in Gokturk. The non-significant changes in oil percentage could be attributed to stress timing at vegetation of the plant. In the current study, severe water stress was applied at the flowering. Nazari et al. (2017) also reported that drought stress at the flowering stage of some safflower did not influence seed oil percentages. In the studies performed on different genotypes of safflower, six different safflower lines were exposed to water stress and subsequently followed by rehydration. The oil yield increased from $24.18 \pm 5.01$ to $26.61 \pm 6.21$ (Bortolheiro and Silva, 2017). However, oil yield significantly decreased under water stress (Nabipour et al., 2007; Ashrafi and Razmjoo, 2010; Ensiye and Khorshid, 2010; Eslam, 2011; Amini et al., 2014). Ozkan and Kulak (2013) reported a non-significant slight increase in oil content of seeds of sesame seedlings exposed to severe water stress. Furthermore, drought stress did not cause significant changes in percentage of seed oil content of safflower species (Nazari et al., 2017).

After oil esterification, the fatty acid compounds in oil were identified using gas chromatography. Of the fatty acid compounds identified for both genotypes, oleic acid, linoleic acid, palmitic acid, stearic acid and behenic acid were of compounds with percentage over 1\% (Table 7).

Their total percentage for treatments were $98.62 \%$ for Remzibey-05 control, $99.02 \%$ for Remzibey-05 SWD, 98.80\% Gokturk control and 99.12\% Gokturk SWD. The yield and percentage can change but the composition of the oil was not affected by severe water stress.

Of the compounds, palmitic acid percentage significantly decreased with severe water stress by $28.30 \%$ for Remzibey- 05 and $15.61 \%$ in Gokturk genotype. No differences regarding percentage of the palmitic acid in control and SWD groups of both genotypes, respectively were found. The decline in palmitic acid under water stress was also reported (Ashrafi and Razmjoo, 2010; Petcu et al., 2001). However, Nazari et al. (2017) reported slight increases in palmitic percentages of for safflower species.

Stearic acid also exhibited similar manner with palmitic acid in both genotypes in response to severe water stress. Stearic acid decreased by $45.36 \%$ in Remzibey- 05 and $26.66 \%$ in Gokturk genotypes. The decreases in percentage of stearic acid were documented (Ashrafi and Razmjoo, 2010). However, Laribi et al. (2009) noted an increase in palmitic acid (110\%) and stearic acid (269\%) and a decline in petroselinic acid $(18.47 \%)$ in Carum carvi under severe water stress.

Oleic acid percentage significantly increased by $7.85 \%$ with severe water stress in Remzibey-05 but the percentage did not significantly vary with severe water stress in Gokturk genotype. Ashrafi and Razmjoo (2010) reported a decline in oleic acid percentage in different safflower genotypes but an increase was documented by Gao et al. (2009). In the study by Ozkan and Kulak (2013), two sesame genotypes were exposed to moderate and severe water stress, documenting that no significant changes in percentage of oleic acid in Cumhuriyet genotype were found while there was a slight but significant change Özberk genotype under severe water stress.

Linoleic acid percentage was not affected by severe water stress in Remzibey-05 genotype but increased by $1.80 \%$ in Gokturk under severe stress conditions. Linoleic acid percentage did not significantly vary in sesame (Cumhuriyet genotype) but increased with stress in sesame (Özberk genotype) (Ozkan and Kulak, 2013). Ashrafi 
and Razmjoo (2010) also reported a decline in percentage of linoleic acid in safflower genotypes.

Oleic acid and linoleic acid ratio increased in Remzibey-05 under severe water stress (ratio: 0.511 and 0.545 for control and SWD, respectively) but it decreased in Gokturk (0.554 and 0.545 for control and SWD, respectively). Laribi et al. (2009) reported decreases in oleic acid and linoleic acid ratio under severe water stress but an increased ratio of oleic acid/linoleic acid was reported (Talha and Osman, 1975).

Percentage of behenic acid increased by $10.64 \%$ and $17.19 \%$ in both genotypes in response to water stress Remzibey-05 and Gokturk, respectively. Behenic acid did not change in sesame seeds in response to water stress (Ozkan and Kulak, 2013; Ozkan, 2018).

Table 7. Effects of water stress on oil yield and fatty acid composition of both safflower genotypes

\begin{tabular}{c|c|c|c|c|c|c}
\hline Fatty acid compounds & $\begin{array}{c}\text { Remzibey-05 } \\
\text { control }\end{array}$ & $\begin{array}{c}\text { Remzibey } \\
\text { 05 SWD }\end{array}$ & $\begin{array}{c}\text { Change } \\
(\boldsymbol{\%})\end{array}$ & $\begin{array}{c}\text { Gokturk } \\
\text { control }\end{array}$ & $\begin{array}{c}\text { Gokturk } \\
\text { SWD }\end{array}$ & $\begin{array}{c}\text { Change } \\
(\%)\end{array}$ \\
\hline Myristic acid & $.0762 \mathrm{a}$ & $.0201 \mathrm{~b}$ & $-73.62 \%$ & .0460 & .0314 & $-31.74 \%$ \\
Palmitic acid & $6.3492 \mathrm{a}$ & $4.5521 \mathrm{~b}$ & $-28.30 \%$ & $4.4915 \mathrm{a}$ & $3.7903 \mathrm{~b}$ & $-15.61 \%$ \\
Palmitoleic acid & $.0665 \mathrm{~b}$ & $.0918 \mathrm{a}$ & $38.05 \%$ & .0759 & .0932 & $22.79 \%$ \\
Heptadecanoic acid & .0316 & .0256 & $-18.99 \%$ & .0244 & .0163 & $-33.20 \%$ \\
Cis-10Heptadecanoic & .0674 & .0757 & $12.31 \%$ & $.0750 \mathrm{~b}$ & $.0825 \mathrm{a}$ & $10.00 \%$ \\
Stearic acid & $2.1725 \mathrm{a}$ & $1.1871 \mathrm{~b}$ & $-45.36 \%$ & $1.2532 \mathrm{a}$ & $.9191 \mathrm{~b}$ & $-26.66 \%$ \\
Oleic acid & $29.8967 \mathrm{~b}$ & $32.2424 \mathrm{a}$ & $7.85 \%$ & 32.7382 & 32.8169 & $0.24 \%$ \\
Linoleic acid & 58.4864 & 59.1422 & $1.12 \%$ & $59.0845 \mathrm{~b}$ & $60.1460 \mathrm{a}$ & $1.80 \%$ \\
Arachidic acid & $.2454 \mathrm{a}$ & $.1163 \mathrm{~b}$ & $-52.61 \%$ & .1557 & .1136 & $-27.04 \%$ \\
Cis11Eicosenoic acid & .0688 & .0762 & $10.76 \%$ & .0727 & .0762 & $4.81 \%$ \\
Linolenic acid & $.1985 \mathrm{~b}$ & $.2755 \mathrm{a}$ & $38.79 \%$ & .2591 & .2748 & $6.06 \%$ \\
Heneicosanoic acid & $.1916 \mathrm{a}$ & $.0724 \mathrm{~b}$ & $-62.21 \%$ & .0484 & .0331 & $-31.61 \%$ \\
Behenic acid & $1.7107 \mathrm{~b}$ & $1.8928 \mathrm{a}$ & $10.64 \%$ & 1.2362 & 1.4487 & $17.19 \%$ \\
Lignoceric acid & .0970 & .0985 & $1.55 \%$ & .1034 & .1055 & $2.03 \%$ \\
Oilyield $(\%)$ & 27.89 & 29.49 & 1.60 & $25.48 \mathrm{~b}$ & $27.85 \mathrm{a}$ & $2.37 \%$ \\
\hline
\end{tabular}

SWD: Severe water deficit; Means for same genotypes with different superscripts (a-b) are significantly different according to Student $t$ test $(\alpha=0.05)$

\section{Fatty acid unsaturation degree}

Based on our experimental data (Table 8), lipids extracted from safflower seeds are dominated by $\mathrm{C} 16$ and $\mathrm{C} 18$ fatty acids which are common in higher plants (Rebey et al., 2017). Analysis of fatty acid composition indicated that safflower seeds in control plants of Remzibey-05 genotype were characterized by a high proportion of polyunsaturated fatty acids (PUFA) $(58.68 \%$ ) versus $30.10 \%$ of monounsaturated fatty acids (MUFA) and $10.87 \%$ of saturated fatty acids. SWD significantly decreased saturated fatty acids (SFA) whereas significantly increased MUFA, UFA and UFA/SFA. However, SWD did not elicit any significant changes in PUFA in Remzibey-05 genotype.

In control groups, safflower seeds in control plants of Gokturk genotype were characterized by a high proportion of polyunsaturated fatty acids (PUFA) $(59.34 \%$ ) 
versus $32.96 \%$ of monounsaturated fatty acids (MUFA) and $7.36 \%$ of saturated fatty acids. SWD significantly decreased saturated fatty acids (SFA) whereas significantly increased PUFA, UFA and UFA/SFA. However, SWD did not elicit any significant changes in MUFA in Gokturk genotype.

Fatty acid unsaturation degree has been considered important in maintenance of membrane fluidity and providing optimal environment for proper membrane functions (Xu and Beardall, 1997; Rebey et al., 2017). In safflower seeds, under control and SWD, the unsaturated fatty acid (UFA) to saturated fatty acid (SFA) ratio was 8.17 and 11.54, respectively for genotype Remzibey-05. UFA/SFA was 12.55 (control) and 14.48 (SWD) for Gokturk genotype. Both genotypes exhibited similar manner regarding fatty acid unsaturation degree.

Table 8. Fatty acid unsaturation degree of genotypes in response to water stress

\begin{tabular}{c|c|c|c|c|c|c}
\hline & \multicolumn{3}{|c|}{ Genotype: Remzibey-05 } & \multicolumn{3}{c}{ Genotype: Gokturk } \\
\hline $\begin{array}{c}\text { Fatty acid unsaturation } \\
\text { degree }\end{array}$ & Control & SWD & $\begin{array}{c}\text { Change } \\
(\%)\end{array}$ & Control & SWD & $\begin{array}{c}\text { Change } \\
(\%)\end{array}$ \\
\hline SFA & $10.87 \mathrm{a}$ & $7.96 \mathrm{~b}$ & $-26.77 \%$ & $7.36 \mathrm{a}$ & $6.46 \mathrm{~b}$ & $-12.23 \%$ \\
MUFA & $30.10 \mathrm{~b}$ & $32.49 \mathrm{a}$ & $7.94 \%$ & 32.96 & 33.07 & $0.33 \%$ \\
PUFA & 58.68 & 59.42 & $1.26 \%$ & $59.34 \mathrm{~b}$ & $60.42 \mathrm{a}$ & $1.82 \%$ \\
UFA & $88.78 \mathrm{~b}$ & $91.90 \mathrm{a}$ & $3.51 \%$ & $92.31 \mathrm{~b}$ & $93.49 \mathrm{a}$ & $1.28 \%$ \\
UFA/SFA & $8.17 \mathrm{~b}$ & $11.54 \mathrm{a}$ & $41.25 \%$ & $12.55 \mathrm{~b}$ & $14.48 \mathrm{a}$ & $15.38 \%$ \\
\hline
\end{tabular}

SWD: Severe water deficit; Means for same genotypes with different superscripts (a-b) are significantly different according to Student t test $(\alpha=0.05)$

However, UFA/SFA was significantly decreased with rising water deficit levels, indicating that severe water stress causes a decline in the passive membrane permeability (Rebey et al., 2017) and coupling with an increase of cellular membrane rigidity (Monteiro de Paula et al., 1993). Herewith, plant might protect itself against possible accumulation oxidative stressors through modifying or re-structuring the membranes with less unsaturated fatty acids.

\section{Correlations between major fatty acids and oil yield}

Along with the present study, two correlation analyses for fatty acids were done (Tables 9-10). In the first correlation analysis (Table 9), all data obtained from both genotypes were pooled- not considering the experimental groups- and then correlated. According to the correlation coefficients, palmitic acid was positively correlated with stearic acid $(r=.955 ; p<0.01)$, oleic acid $(r=.882 ; p<0.01)$ but negatively correlated with behenic acid $(r=-.680 ; p<0.05)$. Stearic acid was positively correlated with oleic acid $(r=.938 ; p<0.01)$ but negatively correlated with linoleic acid $(r=-.917 ; p<0.01)$ and behenic acid $(r=-.650 ; p<0.05)$. Oleic acid was negatively correlated with linoleic acid $(r=-.0996 ; p<0.01)$.

According to the second correlation analysis done in order to determine whether correlation coefficients vary depending control and stress groups (Table 10), in control group, palmitic acid was positively and significantly correlated with linoleic acid $(r=.850 ; p<0.05)$ but in stress group, palmitic acid was again positively correlated but not significant. Also, palmitic acid was negatively and significantly correlated with 
behenic acid $(r=-.831 ; p<0.05)$ but in stress groups, the coefficient was .060 and not significant. Oleic acid was positively and significantly correlated with behenic acid $(r=.980 ; p<0.01)$ in control group. However, the coefficient strongly shifted towards negative correlation from .980 to -.494. As expected, opposite changes were observed between linoleic acid and behenic acid from -.993 to .537 (Table 10).

Table 9. Correlations between major fatty acids and oil yield in safflower seeds $(n=12)$

\begin{tabular}{c|c|c|c|c|c|c}
\hline & $\begin{array}{c}\text { Palmitic } \\
\text { acid }\end{array}$ & $\begin{array}{c}\text { Stearic } \\
\text { acid }\end{array}$ & $\begin{array}{c}\text { Oleic } \\
\text { acid }\end{array}$ & $\begin{array}{c}\text { Linoleic } \\
\text { acid }\end{array}$ & $\begin{array}{c}\text { Behenic } \\
\text { acid }\end{array}$ & Oil yield \\
\hline Palmitic acid & 1 & & & & & \\
Stearic acid & $.955^{* *}$ & 1 & & & & \\
Oleic acid & $.882^{* *}$ & $.938^{* *}$ & 1 & & & \\
Linoleic acid & $-.917^{* *}$ & $-.961^{* *}$ & $-.996^{* *}$ & 1 & & \\
Behenic acid & $-.680^{*}$ & $-.650^{*}$ & -.376 & .442 & 1 & \\
Oil yield & -.332 & -.296 & -.181 & .217 & .302 & 1 \\
\hline
\end{tabular}

$* \mathrm{p}<0.05 * * \mathrm{p}<0.01$

Table 10. Correlations between major fatty acids in control and SWD respectively $(n=6)$

\begin{tabular}{|c|c|c|c|c|c|c|}
\hline & $\begin{array}{c}\text { Palmitic } \\
\text { acid }\end{array}$ & $\begin{array}{c}\text { Stearic } \\
\text { acid }\end{array}$ & $\begin{array}{l}\text { Oleic } \\
\text { acid }\end{array}$ & $\begin{array}{l}\text { Linoleic } \\
\text { acid }\end{array}$ & $\begin{array}{c}\text { Behenic } \\
\text { acid }\end{array}$ & $\begin{array}{c}\text { Oil } \\
\text { yield }\end{array}$ \\
\hline Palmitic acid & 1 & & & & & \\
\hline $\begin{array}{c}\text { Stearic acid control } \\
\text { SWD }\end{array}$ & $\begin{array}{l}.185 \\
-.730\end{array}$ & 1 & & & & \\
\hline $\begin{array}{l}\text { Oleic acid control } \\
\text { SWD }\end{array}$ & $\begin{array}{l}-.882 * \\
-.820^{*}\end{array}$ & $\begin{array}{l}-.426 \\
.317\end{array}$ & 1 & & & \\
\hline $\begin{array}{c}\text { Linoleic Acid control } \\
\text { SWD }\end{array}$ & $\begin{array}{l}.850^{*} \\
.639\end{array}$ & $\begin{array}{l}.418 \\
-.189\end{array}$ & $\begin{array}{l}-.990^{* *} \\
-.924^{* *}\end{array}$ & 1 & & \\
\hline $\begin{array}{c}\text { Behenic acid control } \\
\text { SWD }\end{array}$ & $\begin{array}{c}-.831^{*} \\
.060\end{array}$ & $\begin{array}{l}-.335 \\
.603 \\
\end{array}$ & $\begin{array}{l}.980^{* *} \\
-.494 \\
\end{array}$ & $\begin{array}{l}.993^{* *} \\
.537\end{array}$ & 1 & \\
\hline $\begin{array}{l}\text { Oil yield control } \\
\text { SWD }\end{array}$ & $\begin{array}{l}-.175 \\
-.399\end{array}$ & $\begin{array}{l}-.437 \\
.241\end{array}$ & $\begin{array}{l}.276 \\
.481\end{array}$ & $\begin{array}{l}-.267 \\
-.246\end{array}$ & $\begin{array}{l}.201 \\
.056\end{array}$ & 1 \\
\hline
\end{tabular}

${ }^{*} \mathrm{p}<0.05 ; * * \mathrm{p}<0.01 ;$ SWD: severe water deficit

\section{Effects of water stress on seed mineral content of safflower}

The changes mineral contents in both genotypes with respect to the water stress treatments were statistically significant (Table 11). For Remzibey-05 genotype, $\mathrm{K}$ and $\mathrm{Mg}$ content significantly increased and as expectedly $\mathrm{Na}$ content significantly decreased. However, micro elements did not significantly differ as a response to severe water stress. For Gokturk genotype, K content significantly increased with severe stress. In similar to the Remzibey-05 genotype, there were decreases in $\mathrm{Na}$ content and increase in $\mathrm{Mg}$ content in Gokturk genotype. However, those changes were not statistically significant. $\mathrm{Mg}$ content diminished with drought (Grabaová and Martinková, 2001). Of the micro elements, $\mathrm{Cu}$ content significantly decreased with stress. The changes in content of micro elements were significant. 
Any external stimuli-mediated internal changes in plant metabolism cause perturbations and pose impairments in mineral uptake and their translocation in the plants. Hu and Schmidhalter (2005) highlighted that the water stress induced- nutrient reductions might be attributed to the low transpiration ratio, decreased active transport and disrupted membrane permeability. In the former reports, $\mathrm{K}$ content decreased under drought conditions (Mahouachi, 2007). However, Ozkan and Kulak (2013) examined the $\mathrm{K}$ content in seeds of two genotypes of sesame, genotypes exhibited opposite behaviour of $\mathrm{K}$ accumulation in response to severe water stress. Arjenaki et al. (2012) reported the changes mineral elements of two wheat varieties contrasting drought stress, documenting that tolerant varieties had the highest value of $\mathrm{K}$ while sensitive variety had the highest value of Na. Along with the study, Remzibey-05 had the highest values of both $\mathrm{K}$ and $\mathrm{Na}$ in comparison with Gokturk. Furthermore, when evaluated the growth and yield, all parameters except 1000-seed weight favoured for Remzibey-05 genotype, which seems to be more tolerant against severe water stress.

Overall, it must be highlighted that the mineral uptake and sequential accumulation or partitioning of the minerals thought out the complex plant system are dependent many factors including species, genotypes, cultivars, age of the plant and then stress type and duration of the stress, timing of the stress (pre-flowering, flowering and postflowering vegetative stage). Up to best knowledge and survey of the literature, the studies regarding with interaction of mineral uptake and following processes in response to water stress are scarce even though there are many studies focusing only the last accumulation and content of the status. Forthcoming studies are required to focus on the whole plant system response in terms of minerals and their fate after subjection to the water stress.

Table 11. Water stress treatments on the mineral content of safflower seed ( $\left.\mathrm{mg} \mathrm{kg}^{-1}\right)$

\begin{tabular}{c|c|c|c|c|c}
\hline \multirow{2}{*}{} & \multicolumn{2}{|c|}{ Remzibey-05 } & \multicolumn{2}{c|}{ Gokturk } & \multirow{2}{*}{ F values } \\
\cline { 2 - 5 } & Control & SWD & Control & SWD & \\
\hline $\mathrm{K}$ & $6872.00 \pm 128.01 \mathrm{~b}$ & $7510.67 \pm 173.50 \mathrm{a}$ & $6405.00 \pm 213.58 \mathrm{c}$ & $7004.67 \pm 121.78 \mathrm{~b}$ & $36.162^{* *}$ \\
$\mathrm{Na}$ & $831.00 \pm 10.13 \mathrm{a}$ & $660.19 \pm 60.67 \mathrm{~b}$ & $347.80 \pm 7.700 \mathrm{c}$ & $318.83 \pm 23.99 \mathrm{c}$ & $167.464^{* *}$ \\
$\mathrm{Mg}$ & $624.90 \pm 10.55 \mathrm{c}$ & $685.37 \pm 15.84 \mathrm{~b}$ & $890.63 \pm 34.40 \mathrm{a}$ & $928.40 \pm 14.70 \mathrm{a}$ & $152.702^{* *}$ \\
$\mathrm{Fe}$ & $40.62 \pm 3.49 \mathrm{~b}$ & $42.30 \pm 6.14 \mathrm{~b}$ & $50.61 \pm 4.02 \mathrm{a}$ & $51.28 \pm 3.36 \mathrm{a}$ & $4.754^{*}$ \\
$\mathrm{Cu}$ & $4.63 \pm 0.26 \mathrm{c}$ & $4.52 \pm 0.28 \mathrm{c}$ & $14.66 \pm 0.81 \mathrm{a}$ & $12.33 \pm 1.67 \mathrm{~b}$ & $91.204^{* *}$ \\
$\mathrm{Zn}$ & $32.24 \pm 2.99 \mathrm{~b}$ & $36.96 \pm 5.16 \mathrm{~b}$ & $47.28 \pm 2.45 \mathrm{a}$ & $50.15 \pm 4.05 \mathrm{a}$ & $14.796^{* *}$ \\
\hline
\end{tabular}

SWD: severe water deficit. Means \pm SD in the same row by the same letter are not significantly different to the test of Duncan $(\alpha=0.05) . * * p<0.01 ; * \mathrm{p}<0.05$

\section{Principal components analysis (PCA) of genotypes}

PCA is of the powerful statistical tools in discrimination of the samples based on identified components. Along with the study, two genotypes under two experimental groups with their fatty acid profiles were submitted to Principal Component Analysis. Accordingly, components extracted (Table 12), total variance explained (Table 13) and 2D visualization of the experimental groups (Fig. 1) were obtained. Herewith, the first component (factor) explained $76.476 \%$ of total variances. The second and third components explained $18.965 \%$ and $45.596 \%$ of total variances respectively. Experimental groups were well-discriminated, clarified and identified using PCA, 
documenting that any external deviation from regular irrigation of the plants would cause changes in fatty acid metabolites with their percentage. Herein, genotype Remzibey-05 grown under control groups was quite differentiated from other groups (Fig. 1).

Table 12. Components extracted based on fatty acid compounds corresponding to the their loadings

\begin{tabular}{c|c|c|c}
\hline Components & PC 1 & PC 2 & PC 3 \\
\hline Myristic acid & -0.26061 & -0.2416 & 0.2832 \\
Palmitic acid & -0.294 & 0.049671 & 0.045667 \\
Palmitoleic acid & 0.26381 & 0.25974 & 0.11928 \\
Heptadecanoic acid & -0.27315 & 0.10474 & -0.40634 \\
Cis-10Heptadecanoic & 0.28756 & -0.024918 & 0.2695 \\
Stearic acid & -0.29412 & 0.0032959 & 0.10548 \\
Oleic acid & 0.28051 & -0.10805 & -0.3063 \\
Linoleic acid & 0.26744 & -0.042402 & 0.50497 \\
Arachidic acid & -0.28525 & -0.1282 & 0.17041 \\
Cis11Eicosenoic acid & 0.27601 & 0.2089 & -0.053246 \\
Linolenic acid & 0.28407 & 0.087706 & -0.27679 \\
Heneicosanoic acid & -0.28516 & 0.10642 & 0.22612 \\
Behenic acid & -0.089875 & 0.56431 & 0.046164 \\
Lignoceric acid & 0.23315 & -0.34263 & 0.24914 \\
Oilyield $(\%)$ & 0.0057603 & 0.57592 & 0.28634 \\
\hline \multicolumn{2}{|c}{}
\end{tabular}

Table 13. Total variance explained

\begin{tabular}{c|c|c}
\hline PC & Eigenvalue & \% variance \\
\hline 1 & 114.714 & 76.476 \\
2 & 28.447 & 18.965 \\
3 & 0.683934 & 45.596 \\
\hline
\end{tabular}

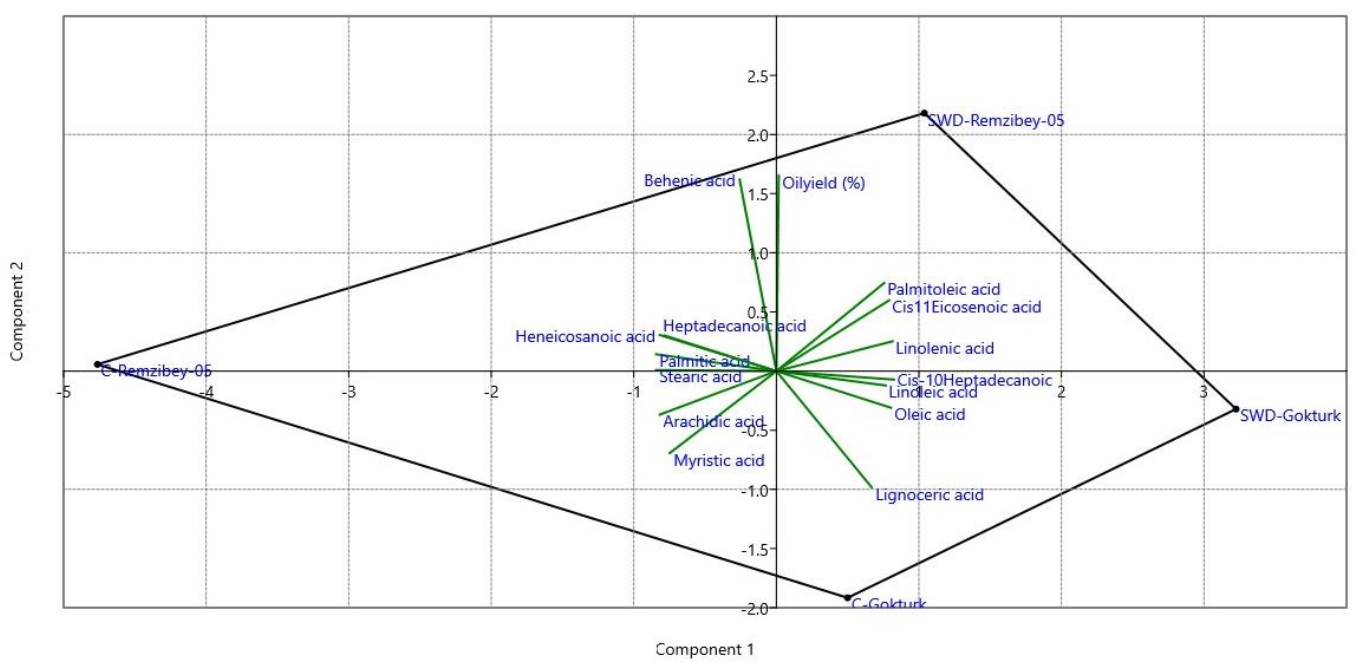

Figure 1. Principal component analysis of genotypes corresponding to the control and severe water stress 


\section{Heatmap construction for genotypes for their fatty acid profile corresponding to control and stress conditions}

According to the heatmap (Fig. 2), arachidic acid, myristic acid, stearic acid, palmitic acid and heneicosanoic acid were more pronounced under control conditions but SWD suppressed their content. SWD increased behenic acid, linoleic acid, cis-11-eicosanoic acid and palmitoleic acid in Remzibey-05 genotype.

SWD topped the percentage of linoleic acid, cis-10-heptadecanoic acid, lignoceric acid, linoleic acid, oleic acid, cis-11-eicasenoic acid and palmitoleic acid in comparison with the control group of Gokturk.

As seen in Figure 2, control and SWD experimental groups exhibited clear different behaviour corresponding to the fatty acid profiles, which were also coupled and supported with principal component analysis (Fig. 1).

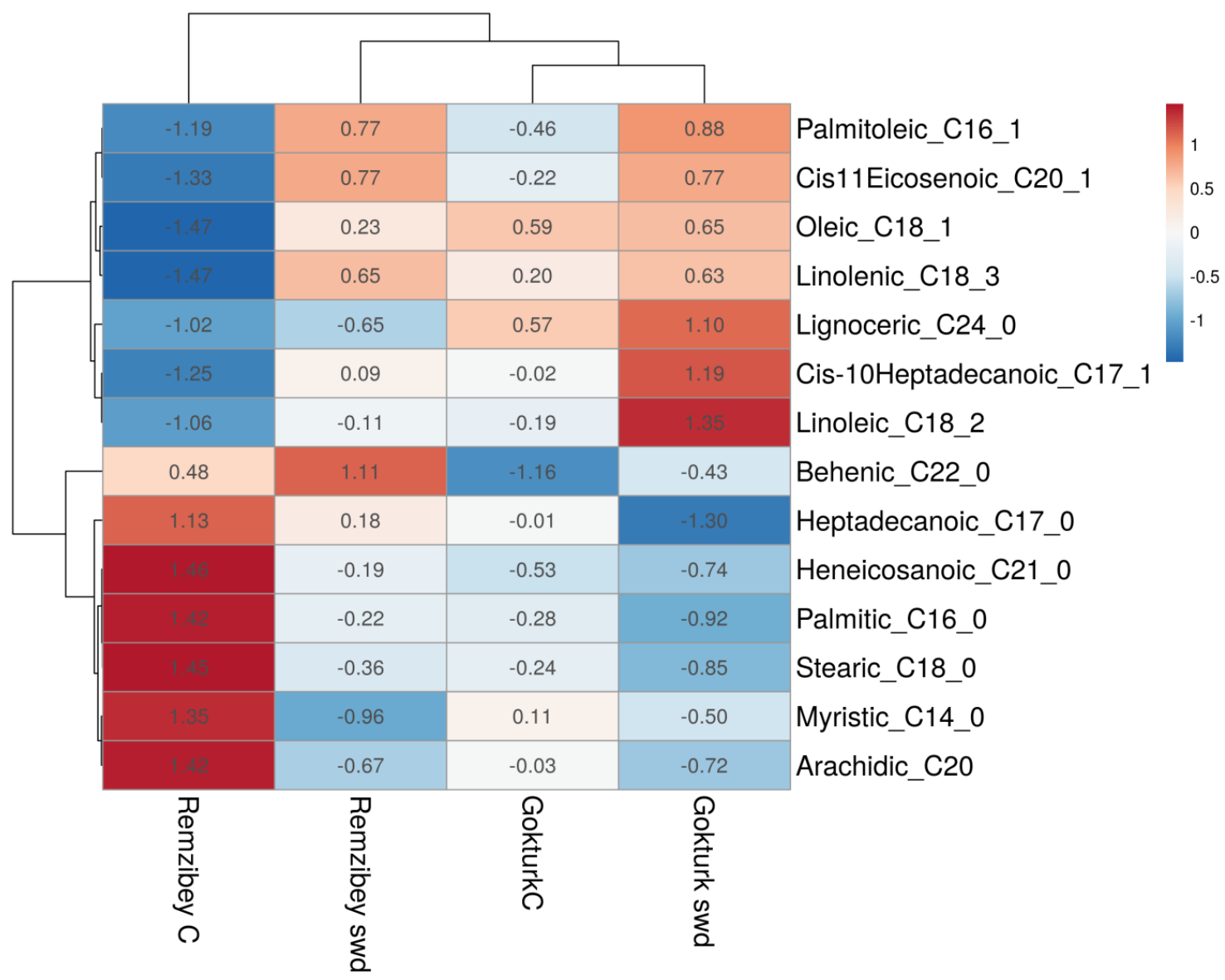

Figure 2. Heatmap constructed for both genotypes concerned with fatty acid profile corresponding to control and stress groups

\section{Conclusion}

The present study was designed to investigate the effects water stress on oil yield combined with their fatty acid profile and mineral contents of seeds of two safflower genotypes. The most important conclusions of this study are:

- Regarding growth and yield parameters under stress, Remzibey-05 genotype had higher values except 1000-seed weight but the values were not significant. 
- Capsule number differences were reported to be significant under stress.

- Oil yield increased under stress conditions for both genotypes.

- UFA/SFA was significantly increased with stress for both genotypes.

- For Remzibey-05 genotype, $\mathrm{K}$ and $\mathrm{Mg}$ content significantly increased and as expectedly $\mathrm{Na}$ content significantly decreased. However, micro elements did not significantly differ as a response to severe water stress. For Gokturk genotype, K content significantly increased with severe stress.

Finally, genotypes exhibited similar behaviour regarding unsaturation degree of the oil, also increments in their oil yield.

For the forthcoming studies, field experiments regarding those genotypes should be performed since the present study was study was carried under controlled green house conditions. The study can be deemed as preliminary study to ascertain some basic properties of the two safflower genotypes under limited water sources. Moreover, more genotypes of the safflower can be screened for their performance and then a selection concerning high tolerant against low water content of soils for genotypes can be made.

\section{REFERENCES}

[1] Ahmed, N., Chowdhry, M. A., Khaliq, I., Maekawa, M. (2016): The inheritance of yield and yield components of five wheat hybrid populations under drought conditions. Indonesian Journal of Agricultural Science 8(2): 53-59.

[2] Al-Barrak, K. M. (2006): Irrigation interval and nitrogen level effects on growth and yield of canola (Brassica napus L.). - Scientific Journal of King Faisal University (Basic and Applied Sciences) 7(1): 87-103.

[3] Amini, H., Arzani, A., Karami, M. (2014): Effect of water deficiency on seed quality and physiological traits of different safflower genotypes. - Turkish Journal of Biology 38(2): 271-282.

[4] Arjenaki, F. G., Jabbari, R., Morshedi, A. (2012): Evaluation of drought stress on relative water content, chlorophyll content and mineral elements of wheat (Triticum aestivum L.) varieties. - International Journal of Agriculture and Crop Sciences 4(11): 726-729.

[5] Ashrafi, E., Razmjoo, K. (2010): Effect of irrigation regimes on oil content and composition of safflower (Carthamus tinctorius L.) cultivars. - Journal of the American OilChemist' Society 87(5): 499-506.

[6] Bettaieb, I., Zakhama, N., Wannes, W. A., Marzouk, B. (2009): Water deficit effects on Salvia officinalis. Fatty acid and essential oils composition. - Scientia Horticulturae 120: 271-275.

[7] Bortolheiro, F. P., Silva, M. A. (2017): Physiological response and productivity of safflower lines under water deficit and rehydration. - Anais da Academia Brasileira de Ciências 89(4): 3051-3066.

[8] Canavar, Ö., Götz, K. P., Koca, Y. O., Ellmer, F. (2014): Relationship between water use efficiency and $\delta^{13}$ isotope discrimination of safflower (Carthamus tinctorius L.) under drought Stress. - Turkish Journal of Field Crops 19(2): 203-211.

[9] Cetinkaya, H., Koc, M., Kulak, M. (2016): Monitoring of mineral and polyphenol content in olive leaves under drought conditions: Application chemometric techniques. Industrial Crops and Products 88: 78-84.

[10] El Sabagh, A., Hossain, A., Barutcular, C., Gormus, O., Ahmad, Z., Hussain, S., Akdeniz, A. (2019): Effects of drought stress on the quality of major oilseed crops: implications and possible mitigation strategies. A Review. - Applied Ecology and Environmental Research 17(2): 4019-4043. 
[11] Ensiye, A., Razmjoo, K. (2010): Effect of irrigation regimes on oil content and composition of safflower (Carthamus tinctorius L.) cultivars. - Journal of American Oil and Chemical Society 87: 499-506.

[12] Eslam, B. P. (2011): Evaluation of physiological indices for improving water deficit tolerance in spring safflower. - Journal of Agricultural Sciences Technology 13: 327-338.

[13] Fahad, S., Bajwa, A. A., Nazir, U., Anjum, S. A., Farooq, A., Zohaib, A., Sadia, S., Nasim, W., Adkins, S., Said, S., Ihsan, M. Z., Alharby, H., Wu, C., Wang, D., Huang, J. (2017): Crop production under drought and heat stress: plant responses and management options. - Frontiers in Plant Science 8: 1147. DOI: 10.3389/fpls.2017.01147.

[14] Gao, J., Hao, X., Thelen, K. D., Robertson, G. P. (2009): Agronomic management system and precipitation effects on soybean oil and fatty acid profiles. - Crop Science 49: 10491057.

[15] Grabaová, S., Martinková, M. (2001): Changes in mineral nutrition of Norway spruce (Picea abies [L.] Karst.) under the impact of drought. - Ekologia Bratislava 20: 46-60.

[16] Hamrouni, I., Salah, H. B., Marzouk, B. (2001): Effects of water-deficit on lipids of sunflower aerial parts. - Phytochemitry 58: 227-280.

[17] Hu, Y., Schmidhalter, U. (2005): Drought and salinity: a comparison of their effects on mineral nutrition of plants. - Journal of Plant Nutrition and Soil Science 168(4): 541-549. DOI: 10.1002/jpln.200420516.

[18] Laribi, B., Bettaieb, I., Kouki, K., Sahli, A., Mougou, A., Marzouk, B. (2009): Water deficit effects on caraway (Carum carvi L.) growth, essential oil and fatty acid composition. - Industrial Crops and Products 30(3): 372-379.

[19] Laribi, B., Kouki, K., Sahli, A., Mougou, A., Marzouk, B. (2011): Essential oil and fatty acid composition of a Tunisian caraway (Carum carvi L.) seed ecotype cultivated under water deficit. - Advances in Environmental Biology 257-265.

[20] Mahouachi, J. (2007): Growth and mineral nutrient content of developing fruit on banana plants (Musa acuminata AAA, 'Grand Nain') subjected to water stress and recovery. Journal of Horticultural Science and Biotechnology 82: 839-844.

[21] Monteiro de Paula, F., Thi, A. T. P., Zuily-Fodil, Y., Ferrari-Iliou, R., Vieira da Silva, J., Mazliak, P. (1993): Effects of water stress on the biosynthesis and degradation of polyunsaturated lipid molecular species in leaves of Vigna unguiculata. - Plant Physiology and Biochemistry 31(5): 707-715.

[22] Nabipour, M., Meskarbashee, M., Yousefpour, H. (2007): The effect of water deficit on yield and yield components of safflower (Carthamus tinctorius L.). - Pakistan Journal of Biological Sciences 10(3): 421-426.

[23] Nazari, M., Mirlohi, A., Majidi, M. M. (2017): Effects of drought stress on oil characteristics of Carthamus species. - Journal of American Oil and Chemistry Society 94: 247-256.

[24] Ozkan, A. (2018): Effect of water deficit on biochemical and growth of sesame in the Middle East Euphrates Valley. - KSÜ Doğa Bilimleri Dergisi 21(1): 91-99.

[25] Ozkan, A., Kulak, M. (2013): Effects of water stress on growth, oil yield, fatty acid composition and mineral content of Sesamum indicum. - Journal of Animal Plant Sciences 23(6): 1686-90.

[26] Petcu, E., Adrian, A., Danil, S. (2001): The effect of drought stress on fatty acid composition in some Romanian sunflower hybrids. - Romanian Agric Res 15: 39-42.

[27] Pouri, K., Mardeh, A. S. S., Sohrabi, Y., Soltani, A. (2019): Crop phenotyping for wheat yield and yield components against drought stress. - Cereal Research Communications 47(2): 383-393.

[28] Prasad, P. V. V., Staggenborg, S. A. (2008): Impacts of Drought and/or Heat Stress on Physiological, Developmental, Growth, and Yield Processes of Crop Plants. - In: Ahuja, L. R. et al. (eds.) Response of Crops to Limited Water: Understanding and Modeling Water Stress Effects on Plant Growth Processes. (Advances in Agricultural Systems Modeling, Series 1.) American Society of Agronomy, Madison, WI. 
[29] Rebey, I. B., Bourgou, S., Rahali, F. Z., Msaada, K., Ksouri, R., Marzouk, B. (2017): Relation between salt tolerance and biochemical changes in cumin (Cuminum cyminum L.) seeds. - Journal of Food and Drug Analysis 25(2): 391-402.

[30] Rubin, R. L., van Groenigen, K. J., Hungate, B. A. (2017): Plant growth promoting rhizobacteria are more effective under drought: a meta-analysis. - Plant and Soil 416(12): 309-323.

[31] Shi, J., Gao, H., Wang, H., Lafitte, H. R., Archibald, R. L., Yang, M., Hakimi, S. M., Mo, H., Habben, J. E. (2017): ARGOS8 variants generated by CRISPR-Cas9 improve maize grain yield under field drought stress conditions. - Plant Biotechnology Journal 15(2): 207-216.

[32] Talha, M., Osman, F. (1975): Effect of soil water stress on water economy and oil composition in sunflower (Helianthus annuus L.). - The Journal of Agricultural Science 84(1): 49-56.

[33] Turk, M. A., Tawaha, A. R. M., Lee, K. D. (2004): Seed germination and seedling growth of three lentil cultivars under moisture stress. - Asian Journal of Plant Sciences 3: 394397.

[34] Vurukonda, S. S. K. P., Vardharajula, S., Shrivastava, M., SkZ, A. (2016): Enhancement of drought stress tolerance in crops by plant growth promoting rhizobacteria. Microbiological Research 184: 13-24.

[35] Xu, X. Q., Beardall, J. (1997): Effect of salinity on fatty acid composition of a green microalga from an Antarctic hypersaline lake. - Phytochemistry 45(4): 655-658.

[36] Zandalinas, S. I., Mittler, R., Balfagón, D., Arbona, V., Gómez-Cadenas, A. (2018): Plant adaptations to the combination of drought and high temperatures. - Physiologia Plantarum 162(1): 2-12. 